\title{
Training in the management of post-traumatic stress disorder in Uganda
}

\author{
Patricia d'Ardenne, ${ }^{1}$ Hanspeter Dorner, ${ }^{2}$ James Walugembe, ${ }^{3}$ \\ Allen Nakibuuka, ${ }^{3}$ James Nsereko, ${ }^{3}$ Tom Onen $^{3}$ and Cerdic Hall ${ }^{2}$
}

'Institute of Psychotrauma, East London NHS Foundation Trust, 61 Bartholomew Close, London EC1A 7BE, UK, email Patricia.Dardenne@eastlondon.nhs.uk; ${ }^{2}$ East London NHS Foundation Trust, London, UK; ${ }^{3}$ Butabika Hospital, Kampala, Uganda

\begin{abstract}
- he aims of this study were to establish the feasibility and effectiveness of training Ugandan mental health workers in the management of post-traumatic stress disorder (PTSD) based on guidelines from the UK National Institute of Health and Clinical Excellence (NICE). The Butabika Link is a mental health partnership between the East London Foundation NHS Trust (ELFT) and Butabika National Psychiatric Referral Hospital, Kampala, Uganda, supported by the Tropical Health Education Trust (THET), and based on the recommendations of the Crisp report (Crisp, 2007). The Link has worked on the principle that the most effective partnership between high-income and low- or middle-income countries is through organisations already delivering healthcare, that is, through the support of existing services. Butabika Hospital is a centre of excellence, serving an entire nation of 30 million people, many of them recovering from 20 years of armed conflict that took place mainly in the north of Uganda. In addition, Uganda has received refugees from conflicts in neighbouring states, including Congo, Rwanda, Kenya, Sudan and Burundi. The Ugandan Ministry of Health's Strategic Plan (2000) has prioritised post-conflict mental disorders and domestic violence, which is reflected in the vision of the Link's work.
\end{abstract}

Epidemiological data on PTSD in Uganda are scarce, though specific studies in war zones suggest a prevalence rate of 39-44\% (Boardman \& Ovuga, 1997; Ovuga et al, 1999, 2008; Liebling-Kalifani et al, 2008).

This paper describes how the East London and Ugandan trauma teams planned, delivered and evaluated a staff training programme in Butabika.

\section{Method}

The London team emailed training slides to Butabika staff. These included an introduction to a neurological model of traumatic memory (Brewin, 2001), trauma-focused cognitivebehavioural therapy (CBT) (Ehlers \& Clark, 2000) and our own work with interpreters (d'Ardenne et al, 2007). THET provided training in the evaluation of partnership projects in June 2007 and also provided a third of the team's travel costs

The London team arrived in September 2007 and spent 2 days with the Butabika staff for a briefing and to meet staff working with traumatised patients. The hospital has access to selective serotonin reuptake inhibitors (SSRIs) and CBT-trained psychology trainees from Makerere University. Training priori- ties were agreed with the executive director of the hospital, the consultant psychiatrist, the lead nurse in trauma and other clinical staff. Managers agreed to release clinicians for 4 days' training and ongoing time for further reading, supervision and trauma-related practice.

There were two key aims of the training:

1 to establish its feasibility - whether it would be possible to arrange workshops for the numbers and range of staff at Butabika

2 to establish its effectiveness - whether it would increase professionals' ability to recognise and diagnose PTSD, and whether local clinical practice for PTSD patients would change.

Workshops were devised to cover:

O first principles of PTSD

O evaluation of trauma work

O child abuse

O psychological treatments of PTSD in adults

O psychological treatments of PTSD in children

O grounding exercises with PTSD patients - theory and practice

O dual representation model of traumatic memory

O identification of 'hot-spots' and revisiting traumatic memory

O case discussion of child soldiers and the management of aggression

O psychological effects of war on children

O group therapy with traumatised adults

O working with interpreters and PTSD.

Four morning workshop sessions were advertised. The format was interactive, with slides, group exercises, roleplays, plenary feedback, discussion and written exercises. Three 90-minute workshops were held per morning, with breaks. Afternoons were spent on feedback, case-note audits and preparation. Forty-one mental health staff attended two or more workshops, including psychiatric nurses, occupational therapists, psychologists, counsellors, psychiatrists, trainee paediatricians and psychiatric clinical officers.

A written quiz was given at each workshop to clarify trauma experience and understanding. Participants were given evaluation sheets including a five-point Likert scale with these questions:

O How understandable was this workshop to you?

O How helpful was this workshop to you personally?

O How relevant was the workshop to your clinical practice with traumatised patients?

O What else would you have liked to learn? 
Table 1 Trainee outcome: mean item ratings on a 5-point Likert scale $(n=18-40$ for attendance at individual workshops)

$\begin{array}{lllll} & \text { Day } 1 & \text { Day } 2 & \text { Day } 3 & \text { Day } 4 \\ \text { How helpful was this workshop? } & 3.2 & 3.2 & 4.0 & 4.2 \\ \text { How relevant was this workshop? } & 4.6 & 4.3 & 4.9 & 4.8 \\ \text { How understandable was this workshop? } & 2.0 & 2.5 & 3.0 & 3.9\end{array}$

${ }^{a} 0=$ not at all; $5=$ completely.

The evaluations were scored and discussed, and training was adjusted accordingly. Clinical log-books were distributed to record ongoing changes in clinical practice with PTSD patients. General psychiatric staff identified group projects for their PTSD patients.

\section{Results}

A large majority of the participants (80\%) reported increased confidence in recognising trauma. Outcome scores improved as the training progressed (Table 1). For example, on day $1,25 \%$ of participants could name all PTSD symptoms by DSM-IV criteria and by day 4 this increased to $100 \%$.

Ward groups for PTSD patients were identified to help rape victims, survivors of floods, war-affected children and survivors of childhood sexual abuse. Examples of written feedback, taken from clinical logs and from workshop forms, were published in a THET report in October 2007. Before the training, interventions for these patients were either non-existent or they were given supportive counselling. An education programme for carers was established to inform them of the meaning of intrusions, avoidance and hyperarousal.

Training was followed by further requests for training, reading materials, online supervision and exchange visits. Staff undertook evaluation of their trauma interventions and recorded this in case notes or clinical logs, as reported by the trauma manager.

A strategy has been developed to use the unit as a centre that trains trainers, who will be able to reach rural communities unable to access a national centre. The unit will use psychiatric clinical officers already working across the 16 districts of Uganda to complete and evaluate its training as the next stage of work.

\section{Discussion}

The aims of this study had been to establish the feasibility and effectiveness of training Ugandan mental health workers in the management of PTSD. The Ugandan team requested a Western training and clinical model for severely traumatised patients already in their care.

A PTSD training programme was devised rapidly that could engage significant numbers of clinicians working across mental health settings. Role-play and demonstrations were valued, as were presentations of local cases. Comprehension, utility and relevance improved with time, although data on reliability were affected by extreme ratings at the ends of the scales. London pronunciation, speed of speech and reliance on psychological jargon were quickly altered on feedback from participants.
Training involved cross-cultural and mutual learning. The London team learned how to phase work, about how limited resources can be built up, and about community approaches involving village elders in the rehabilitation of traumatised boy soldiers.

The study had many limits. It was very brief and small, and the training needs of a national referral centre considerably exceeded resources. But it provided hope as a first step and this was acknowledged, with a plan for sustainable training over future years and further exchanges, which continue today.

It is feasible to train mental health staff in Uganda to diagnose and refer PTSD patients. The effectiveness of the training was demonstrated but it will require ongoing evaluation for real and sustained development.

\section{Dedication}

This study is dedicated to the memory of Dr James Walugembe, who died shortly after completing this paper and whose work inspired this training.

\section{Acknowledgements}

The authors thank: the Butabika Hospital staff and in particular, Dr Fred Kigozi, Executive Director; ELFT - Chair Baroness Molly Meacher, who has generously supported the work of the Butabika Link throughout; and the Tropical Health and Education Trust - in particular Karen Peachey, International Director.

\section{References}

Boardman, J. \& Ovuga, E. (1997) Rebuilding psychiatry in Uganda. Psychiatric Bulletin, 21, 649-655.

Brewin, C. (2001) Cognitive and emotional reactions to traumatic events. Implications for short-term intervention. Advances in Mind-Body Medicine, 17, 163-168.

Crisp, N. (2007) The Crisp Report: Global Health Partnerships. The UK Contribution to Health in Developing Countries. Department of Health.

d'Ardenne, P., Farmer, E., Ruaro, L., et al (2007) Not lost in translation: protocols for interpreting trauma-focussed CBT. Behavioural and Cognitive Psychotherapy, 35, 303-316.

Ehlers, A. \& Clark, D. (2000) A cognitive model of posttraumatic stress disorder. Behaviour Research and Therapy, 38, 319-345.

Liebling-Kalifani, H., Ojiambo-Ochieng, R., Marshall A., et al (2008) Violence against women in northern Uganda: the neglected health consequences of war. Journal of International Women's Studies, 9, 174-190.

Ministry of Health (2000) Health Sector Strategic Plan 2000/01-2004/05, at http://www.health.go.ug/docs/HSSPfinalEdition.pdf (accessed December 2008).

Ovuga, E., Boardman, J. \& Oluka, G. (1999) Traditional healers and mental illness in Uganda. Psychiatric Bulletin, 23, 276-279.

Ovuga, E., Oyok, T. \& Moro, T. (2008) Post traumatic stress disorder among former child soldiers attending a rehabilitative service and primary school education in northern Uganda. African Health Sciences, 8, 136-141 